\title{
Efficacy of Subcutaneous Tocilizumab for the Treatment of Refractory Large Vessel Vasculitis in a Patient with Latent Tuberculosis Infection
}

\author{
Girelli $\mathrm{F}^{1^{*}}$, Bezzi $\mathrm{A}^{2}$, Galassi $\mathrm{R}^{3}$, Moretti $\mathrm{A}^{3}$, Tomassetti $\mathrm{S}^{4}$, Ravaglia $\mathrm{C}^{4}$ and Nizzoli $\mathrm{M}^{1}$ \\ ${ }^{1}$ Internal Medicine Unit, Rheumatology service, GB Morgagni Hospital, Forli, Italy \\ ${ }^{2}$ Internal-Rheumatology Unit, Infermi Hospital, Rimini, Italy \\ ${ }^{3}$ Nuclear Medicine Service, GB Morgagni Hospital, Forli, Italy \\ ${ }^{4}$ Pulmonology Unit, GB Morgagni Hospital, Forli, Italy
}

*Corresponding author: Girelli F, Internal Medicine Unit, Rheumatology service, GB Morgagni Hospital - Forlì, Italy, Tel: 39 3474254339, E-mail: francesco.girelli@auslromagna.it

Citation: Girelli F, Bezzi A, Galassi R, Moretti A, Tomassetti S, et al. (2017) Efficacy of Subcutaneous Tocilizumab for the Treatment of Refractory Large Vessel Vasculitis in a Patient With Latent Tuberculosis Infection. SAJ Case Rep 4: 303

Article history: Received: 12 June 2017, Accepted: 29 August 2017, Published: 31 August 2017

\begin{abstract}
Tocilizumab (TCZ), a specific IL-6 inhibitor, has been shown to be effective and well tolerated in the treatment of refractory large-vessel vasculitis with monthly intravenous (i.v) infusions of $8 \mathrm{mg} / \mathrm{Kg}$ of body weight. Our case report has confirmed the efficacy of TCZ also if administered subcutaneously (s.c.) in a patient with large-vessel vasculitis resistant to a combination of corticosteroids (CST) plus methotrexate (MTX). Moreover, reactivation of latent tuberculosis was not observed in our case with isoniazid prophylaxis.
\end{abstract}

Keywords: Tocilizumab; Large Vessel Vasculitis; Latent TB

\section{Introduction}

TCZ, administered in monthly i.v. infusions, is efficacious for the treatment of refractory large-vessel vasculitis in which it may control symptoms and C-reactive protein (CRP) [1-5]. The rationale of the efficacy of TCZ is based on the pathogenic role of the pivotal proinflammatory cytockine IL-6 in several rheumatic disease (such rheumatoid arthritis, Still's diseases and giant cell arteritis) where it promotes the switch from acute to chronic infilammation [6]. Reactivation of latent tuberculosis is a serious possible side effect of immune suppressive therapies [7]. We confirm the efficacy and safety of TCZ in a patient affected by refractory disease, also if administered in weekly s.c. injections.

\section{Case report}

A 67 years old man, smoker (20 packs/y), who went to radical prostatectomy in 2012 for adenocarcinoma and with previous erosive oesophagitis, presented the appearance, in August 2015, of a systemic clinical picture characterized by fever, disabling asthenia, shoulders and hips pain with severe stiffness at rest and CRP markedly elevated $(150 \mathrm{mg} / \mathrm{L}$, normal value $<5)$. Unfortunately, ESR was not performed from the beginning and we continued to use CRP for the biological follow up. Active systemic infections were excluded ( blood, urine and stool coltures, serologic tests for Salmonella, Shigella, Borrelia and Bartonella, hepatitis B and C markers were all normal); no onco-haematological abnormality have been found, with the exception of a MGUS IgA- $\lambda$; also IgG-4 were normal. One CT angiography of the aorta, performed because the chest and abdominal tomodensitometry had shown increased diameter of it, revealed diffuse thickening of its wall and contrast enhancement at the level of the right brachiocephalic trunk. The patient was treated elsewhere with CST therapy (50 mg daily of prednisone equivalent); after an initial improvement, the corticosteroid dosage was gradually reduced by $5 \mathrm{mg}$ per week; the patient showed clinical and biological relapse while tapering the prednisone and was unable to reduce the dose to $<12.5 \mathrm{mg} /$ day; after two relapses, at the end of September and November of the same year, he was admitted to our Unit in December 2015 with disabling asthenia, shoulders and hips pain with severe stiffness 
at rest. It was confirmed marked increase of the CRP, while a PET-CT showed increase of metabolic uptake of FDG of the thoracic aorta and the emergence of the right brachiocephalic trunk with a maximum Standard Uptake Value (SUV) of 2.97 (Figure 1). The diagnosis of large-vessel vasculitis was performed and a combination therapy with s.c. MTX (15 mg weekly) in addition to prednisone $1 \mathrm{mg} / \mathrm{Kg}$ of body weight daily was administered; as the patient showed QuantiFERON positivity, it was introduced prophylactic tuberculosis treatment with isoniazid $300 \mathrm{mg}$ daily [8,9] for nine months. At any attempt of steroid tapering to 12.5 mg daily, the patient showed the recurrence of fever and fatigue, with marked increase of CRP, while the PET-CT showed the disappearance of metabolic hyperactivity in the areas previously described. After about seven months from the introduction of MTX, TCZ at the dosage of $8 \mathrm{mg} / \mathrm{Kg}$ i.v. every 4 weeks was therefore started (patient body weight was $80 \mathrm{Kg}$ ), with the consent of the patient and with the permission of the Commission for Rare Diseases of the Regional Health Service of Emilia-Romagna; each infusion was preceded by paracetamol $1000 \mathrm{mg}$ i.v., methylprednisolone $20 \mathrm{mg}$ i.v. and cetirizine $10 \mathrm{mg}$ orally (p.o). The therapy was well tolerated and, after 3 infusions, we observed the disappearance of symptoms and the normalization of CRP, with steroid tapered to 2.5 daily. Due to hard logistic difficulties of the patient in reaching the hospital for outpatient infusions, in October 2016 it was decided to switch, with the approval of the Rare Disease Commission, to the s.c. formulation at a dose of $162 \mathrm{mg}$ weekly, that the patient still well tolerates with no adverse events after follow up of 6 months.

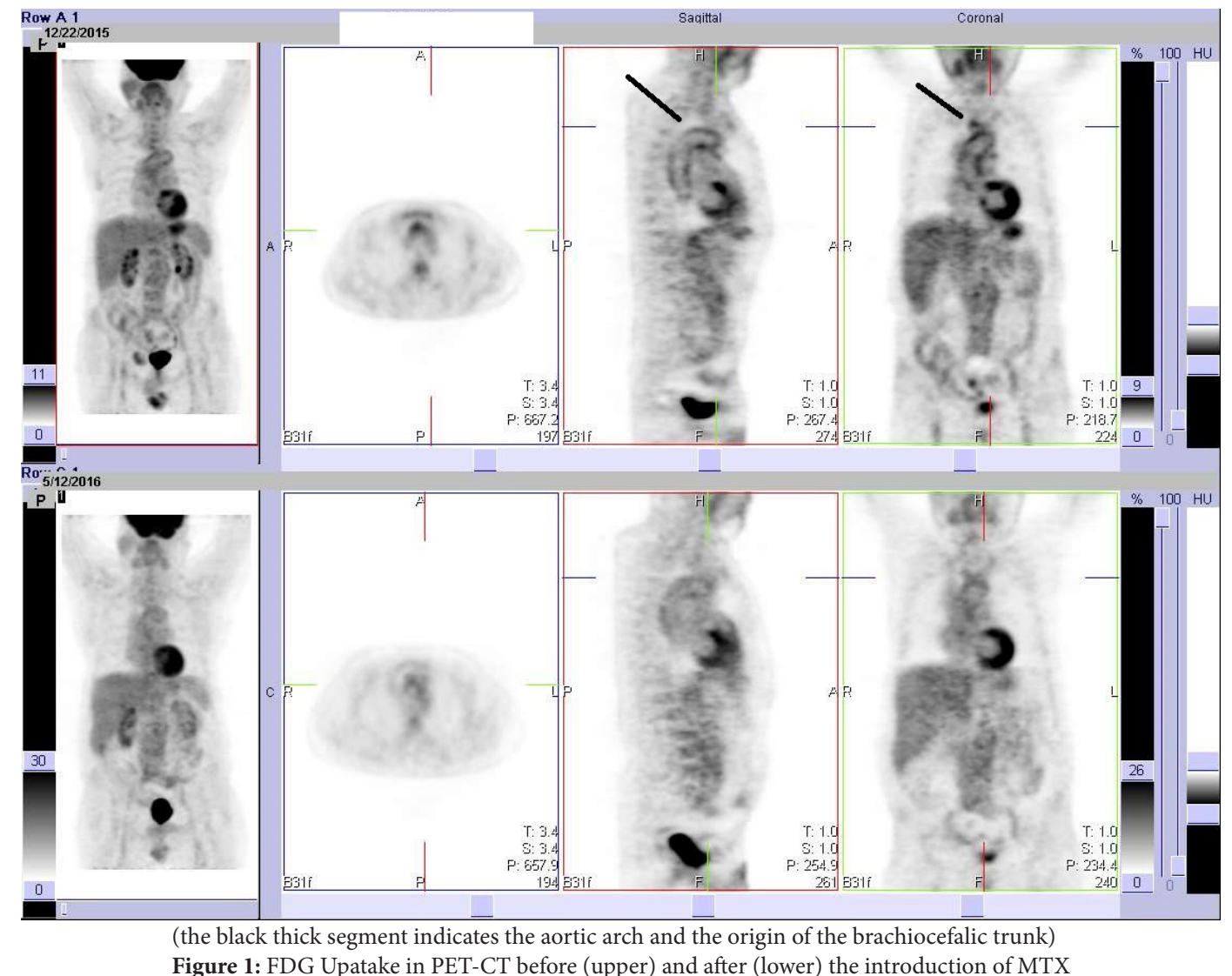

\section{Discussion}

CST are the treatment of choice of large-vessel vasculitis, which may relapse when dosages are tapered or suspended; different strategies have been proposed for the treatment of refractory large-vessel vasculitis, among which the introduction of immunosuppressive and cytotoxic drugs (MTX, azatioprine, cyclophosphamide) or anti TNF- [1-5]. In more recent years, TCZ, a strong IL-6 inhibitor, has been efficaciously employed for the treatment of refractory large-vessel vasculitis, in which it showed to be effective in obtaining the disease remission, with amelioration of clinical manifestations and control of acute-phase reactants; TCZ has been employed mostly in combination with MTX but there are no guidelines about which of the two drugs should be left to mantain the remission [6,10-15]. The disease of our patient was refractory to the treatment with corticosteroids, administered firstly in monotherapy, then in combination with MTX; this latest combination therapy was associated with an improvement of the FDG uptake at the PET-CT but this imaging tecnique, which has good sensitiviy and specificity for the diagnosis of large-vessel vasculitis [16,17], is not considered reliable in the follow up of the biological activity [18]. The introduction of sucutaneous TCZ has led to the persistent regression of symptoms and normalization of the biological activity indices (CRP), which has also persisted until the lowest CTS dosage of $2.5 \mathrm{mg}$ on alternate days (Table 1). The improvement obtained is still persisting six months after the switch from the i.v. to the s.c. formulation. While for the treatment of rheumatoid arthritis s.c. TCZ, at the different dosages of 162 mg weekly and every 14 days, showed a level of efficacy and tolerability comparable to the i.v. way of administration [19,20], to the best of our knowledge in only one previous expercience TCZ has been effecaciously administered subcutaneously for the treatment 
of large vessel vasculitis [21]. The reactivation of latent tuberculosis is one of the possible side effects of immunosuppressive therapy in patients with rheumatic diseases; relating to tocilizumab, the finding of some series of increased incidence of latent tuberculosis reactivation seems to be actually linked to a greater endemicity of the disease [7]; IFN- $\gamma$, which is a crucial molecule in the anti-tuberculosis defense, is inhibited by biological therapy, but the rate of such inhibition seems to be stronger with etanercept and infliximab respect to TCZ which should be preferred in patient with latent tuberculosis infection [22]. Our case has confirmed the safety of TCZ, regardless the way of administration, also in relation to the risk of activation of a latent tuberculosis, providing that adequate prophylaxis be actuated [8,9]. Further controlled studies are needed to confirm the efficacy of TCZ in the treatment of refractory large-vessel vasculitis.

\begin{tabular}{|c|c|c|c|c|c|}
\hline & T (C) & $\begin{array}{c}\text { CRP } \\
\text { (mg/L) }\end{array}$ & $\begin{array}{c}\text { CST } \\
\text { (mg/day) }\end{array}$ & $\begin{array}{c}\text { MTX } \\
(\mathbf{m g} / \text { week) }\end{array}$ & TCZ \\
\hline T0 & 38 & 137 & 75 & 15 & $\begin{array}{c}\text { i.v. } \\
8 \mathrm{mg} / \mathrm{kg} / 4 \text { weeks }\end{array}$ \\
\hline $\mathbf{3}$ months & 36,3 & 1,5 & 6,5 & 15 & $\begin{array}{c}\text { i.v. } \\
8 \mathrm{mg} / \mathrm{kg} / 4 \text { weeks }\end{array}$ \\
\hline $\mathbf{4}$ months & 36,3 & 2,5 & 2,5 & 15 & $\begin{array}{c}\text { s.c. } \\
162 \mathrm{mg} / \text { week }\end{array}$ \\
\hline $\mathbf{1 0}$ months & 36,5 & 0,5 & 1,25 & 15 & $\begin{array}{c}\text { s.c. } \\
162 \mathrm{mg} / \text { week }\end{array}$ \\
\hline
\end{tabular}

T: body temperature, C: Celsius; CRP: CreactiveProtein $(\mathrm{nv}<0.5 \mathrm{mg} / \mathrm{L})$, CST: corticosteroids, prednisone equivalent; MTX: methotrexate; TCZ: tocilizumab; i.v.: intravenous; s.c.:subcutaneously Table 1: Effect of TCZ on temperature and C-reactive Protein

\section{Key points message}

1) Tocilizumab in the treatment of large-vessel vasculitis is efficacious also when administered subcutaneously.

2) Tocilizumab did not reactivate latent tuberculosis after 6 months of therapy in a patient previously treated with isonizide.

\section{References}

1. Weyand CM, Goronzy JJ (2003) Medium- and large-vessel vasculitis. N Engl J Med 349: 160-9.

2. Jover JA, Hernández-García C, Morado IC, Vargas E, Bañares A, et al. (2001) Combined treatment of giant-cell arteritis with methotrexate and prednisone. a randomized, double-blind, placebo-controlled trial. Ann Intern Med 134: 106-14.

3. Hoffman GS, Leavitt RY, Kerr GS, Rottem M, Sneller MC, et al. (1994) Treatment of glucocorticoid-resistant or relapsing Takayasu arteritis with methotrexate. Arthritis Rheum 37: 578-82.

4. Martínez-Taboada VM, Rodríguez-Valverde V, Carreño L, López-Longo J, Figueroa M, et al. (2008) A double-blind placebo controlled trial of etanercept in patients with giant cell arteritis and corticosteroid side effects. Ann Rheum Dis 67: 625-30.

5. Hoffman GS, Merkel PA, Brasington RD, Lenschow DJ, Liang P (2004) Anti-tumor necrosis factor therapy in patients with difficult to treat Takayasu arteritis. Arthritis Rheum 50: 2296-304.

6. Loricera J, Blanco R, Hernández JL, Castañeda S, Mera A, et al. (2015) Tocilizumab in giant cell arteritis: Multicenter open-label study of 22 patients. Semin Arthritis Rheum 44: 717-23.

7. Cantini F, Niccoli L, Goletti D (2014) Tuberculosis risk in patients treated with non-anti-tumor necrosis factor- $\alpha$ (TNF- $\alpha$ ) targeted biologics and recently licensed TNF- $\alpha$ inhibitors: data from clinical trials and national registries. J Rheumatol Suppl 91: 56-64.

8. Nordgaard-Lassen I, Dahlerup JF, Belard E, Gerstoft J, Kjeldsen J, et al. (2012) Guidelines for screening, prophylaxis and critical information prior to initiating anti-TNF-alpha treatment. Dan Med J 59: C4480.

9. Mor A, Bingham CO 3rd, Kishimoto M, Izmirly PM, Greenberg JD, et al. (2008) Methotrexate combined with isoniazid treatment for latent tuberculosis is well tolerated in patients with rheumatoid arthritis: experience from an urban arthritis clinic. Ann Rheum Dis 67: 462-5.

10. Salvarani C, Magnani L, Catanoso M, Pipitone N, Versari A, et al. (2012) Tocilizumab: a novel therapy for patients with large-vessel vasculitis. Rheumatology (Oxford) 51: 151-6.

11. Unizony S, Arias-Urdaneta L, Miloslavsky E, Arvikar S, Khosroshahi A, et al. (2012) Tocilizumab for the treatment of large-vessel vasculitis (giant cell arteritis, Takayasu arteritis) and polymyalgia rheumatica. Arthritis Care Res (Hoboken) 64: 1720-9.

12. Işık M, Kılıç L, Doğan İ, Calgüneri M (2013) Tocilizumab for giant cell arteritis: an amazing result. Rheumatol Int 33: 2961-2.

13. Vinit J, Bielefeld P, Muller G, Besancenot JF (2012) Efficacy of tocilizumab in refractory giant cell arteritis. Joint Bone Spine 79: 317-8.

14. Lurati A, Bertani L, Re KA, Marrazza M, Bompane D, et al. (2012) Successful treatment of a patient with giant cell vasculitis (horton arteritis) with tocilizumab a humanized anti-interleukin-6 receptor antibody. Case Rep Rheumatol 2012: 639612.

15. Della Rossa A, Cioffi E, Elefante E, Ferro F, Parma A, et al. (2014) Systemic vasculitis: an annual critical digest of the most recent literature. Clin Exp Rheumatol 32: S98-105.

16. Stellingwerff MD, Brouwer E, Lensen KJ, Rutgers A, Arends S, et al. (2015) Different Scoring Methods of FDG PET/CT in Giant Cell Arteritis: Need for Standardization. Medicine (Baltimore) 94: e1542.

17. Fatma Alibaz-Öner, Sibel Zehra Aydın, Haner Direskeneli (2015) Recent advances in Takayasu’s arteritis. Eur J Rheumatol 2: 24-30.

18. Cheng Y, Lv N, Wang Z, Chen B, Dang A (2013) 18-FDG-PET in assessing disease activity in Takayasu arteritis: a meta-analysis. Clin Exp Rheumatol 31: S22-7. 19. Burmester GR, Rubbert-Roth A, Cantagrel A, Hall S, Leszczynski P, et al. (2016) Efficacy and safety of subcutaneous tocilizumab versus intravenous tocilizumab in combination with traditional DMARDs in patients with RA at week 97 (SUMMACTA). Ann Rheum Dis 75: 68-74. 
20. Ogata A, Tanimura K, Sugimoto T, Inoue H, Urata Y (2014) Phase III study of the efficacy and safety of subcutaneous versus intravenous tocilizumab monotherapy in patients with rheumatoid arthritis. Arthritis Care Res 66: 344-54.

21. Evans J, Steel L, Borg F, Dasgupta B (2016) Long-term efficacy and safety of tocilizumab in giant cell arteritis and large vessel vasculitis. RMD Open 2: e000137.

22. Ogata A, Mori M, Hashimoto S, Yano Y, Fujikawa T, et al. (2010) Minimal influence of tocilizumab on IFN-gamma synthesis by tuberculosis antigens. Mod Rheumatol 20: 130-3. 